\title{
A VISÃO MÉDICA E ACADÊMICA DA PSIQUIATRIA: UM ESTUDO QUANTITATIVO EM UM CENTRO UNIVERSITÁRIO PARTICULAR DO OESTE DO PARANÁ
}

\section{MEDICAL AND ACADEMIC VIEW OF PSYCHIATRY: A QUANTITATIVE ANALYSIS IN A PRIVATE UNIVERSITY CAMPUS IN WESTERN PARANA}

\begin{abstract}
Laura Luísa Pompeo1*, Gabriela Cristina Dantas ${ }^{1}$, Julia Amaro Galão1, Andréa Maria Rigo Rise ${ }^{2}$, Rui S. S. A. De Almeida ${ }^{3}$

'Acadêmico de Medicina do Centro Universitário Fundação Assis Gurgacz. ${ }^{2}$ Médica psiquiatra e professora do curso de Medicina do Centro Universitário da Fundação Assis Gurgacz. ${ }^{3}$ Médico cirurgião cardiovascular, coordenador e professor do curso de Medicina do Centro Universitário da

Fundação Assis Gurgacz.

* Autor Correspondente: laura_pompeo@hotmail.com , https://orcid.org/0000-0002-2399-5843
\end{abstract}

DOI: 10.35984/fjh.v2i2.191

\section{RESUMO}

Objetivo: Este artigo tem como objetivo comparar as diferentes visões sobre a psiquiatria ao longo do curso de medicina e da formação médica. Métodos: Foram avaliadas antecedentes pessoais e familiares relativos a doença mental e aplicado o questionário AQ-9 de Corrigan em 98 alunos do $1^{\circ}$ ao $6^{\circ}$ ano de medicina do Centro Universitário da Fundação Assis Gurgacz e em 06 profissionais da área médica, para avaliação do estigma. Resultados: Os resultados apontaram para a ausência de influências da formação médica na percepção de estigma sobre a psiquiatria ou doença mental, e sim maior evidência para fatores extrínsecos. Conclusão: através desta análise, foi possível concluir que pode não haver uma relação específica entre o estigma dentro da psiquiatria e o grau de instrução acadêmica dentro do curso de medicina.

Palavras-chave: Estigma. Psiquiatria. Doença mental.

\begin{abstract}
Goal: This article seeks to compare the different views of psychiatry throughout medical school and career. Methods: Previous personal and family experiences with mental illnesses have been evaluated and the Corrigan AQ-9 questionnaire was applied to 98 students ranging from the first to the sixth year of the Fundação Assis Gurgacz University Center Medical School and to six practitioners of the medical field to evaluate stigma. Results: The results pointed to the absence of influence from the medical formation over the perception of stigma on psychiatry or mental illness, but to a higher evidence of external factors. Conclusion: through this analyses it was possible to conclude that there is no particular relation between the stigma surrounding psychiatry and the level of academic instruction within medical schooling.
\end{abstract}

Keywords: Stigma. Psychiatry. Mental illness.

\section{INTRODUÇÃO}

A OMS define a perturbação mental como um desajuste do pensamento e das emoções produzida por inadequação ou deterioração do funcionamento psicossocial em pendência de fatores biológicos, psicológicos e sociais (XAVIER et al., 2014). Tais fatores causam, além do prejuízo mental, certo estranhamento e /ou rejeição pelas pessoas, que têm dificuldade em compreender as nuances das doenças mentais. 
Dessa forma, o estigma da doença mental permanece um assunto complexo na sociedade, culminando em efeitos nefastos nos doentes mentais, retardando ou impedindo a procura de cuidados de saúde, a instituição ou manutenção de tratamento e a sua recuperação (CONFUNDIMENTO; RAMALHO, 2014). Desse modo, essa pesquisa abordará a visão médica e acadêmica em relação à psiquiatria, observando as dificuldades enfrentadas pelos médicos clínicos e/ou psiquiatras em fornecer e pelos pacientes em alcançar tratamento, causadas pelo estigma que cerca esta área da medicina.

No decorrer da história da humanidade, os pacientes psiquiátricos foram chamados de loucos, doidos, mentecaptos, insanos, sandeus, desassisados, dementes ou alienados mentais e por terem comportamentos considerados socialmente incômodos ou perigosos, eram frequentemente reclusos em cadeias públicas, em cômodos particulares, ou ainda, nas enfermarias dos hospitais de caridade (ODA; DALGALARRONDO, 2016). A respeito da historia do tratamento realizado com os ,até então, chamados de "loucos" no Brasil no século XX:

Através de todo o período colonial, os alienados, os idiotas, os imbecis foram tratados de acordo com suas posses. Os abastados e relativamente tranquilos, eram tratados em domicílio e às vezes enviados à Europa (...). Se agitados punham-nos em algum cômodo separado, soltos ou amarrados, de acordo com a intensidade da agitação. Os mentecaptos pobres, tranquilos vagueavam pelas cidades, aldeias ou pelo campo (...). Os agitados eram recolhidos às cadeias onde barbaramente amarrados e piormente alimentados muitos faleceram mais ou menos rapidamente (ODA; DALGALARRONDO, 2016).

Segundo Marques et al, (2010), o processo de urbanização e a consequente necessidade de manutenção de ordem das cidades em desenvolvimento resultaram em maiores pressões sociais, que exigiram restrição a livre circulação dos chamados alienados, visto que o espaço urbano estabeleceria novos padrões de controle social, diferentes daqueles próprios à vida rural, supostamente mais complacente com tal circulação.

A partir disso, chegavam cada vez mais reclamações ao governo, as quais reivindicavam que o mesmo tomasse providencias e retirasse de circulação os desocupados ou desordeiros, que eram encaminhados comumente às prisões da época. Já os casos com evidentes distúrbios mentais, eram destinados às enfermarias dos hospitais da Irmandade de Misericórdia, porém sem tratamento médico algum, visto que se tratava de uma associação filantrópica leiga católica (ODA, 2011). ODA et at, (2016) descreveu o local como sem "regímen, limpeza, polícia e caridade", considerando "calabouço" um nome mais apropriado ao lugar.

A criação dos hospícios exclusivos para os alienados se deu a partir da Santa Casa da Corte e de outros hospitais de caridade das principais cidades brasileiras no início do século XIX, que mantiveram sob as mesmas condições miseráveis repartições reservadas aos insanos, originando assim, os hospícios exclusivos para os alienados. Vale lembrar que os termos "asilo" e "hospício" ou "hospital" eram usados como sinônimos, segundo documentos da época, denotando hospedagem destinada àqueles que fossem dependentes de doações, como órfãos, recémnascidos abandonados, mendigos, etc. Foi o imperador Dom Pedro II quem fundou o primeiro hospício exclusivo para os alienados, o Hospício Pedro II, inaugurado em 1852, porém somente no início do século XX é que os médicos tomaram a direção desses locais e foi assim que a história dos doentes mentais asilados nos hospitais psiquiátricos brasileiros tornou-se lamentavelmente parecida àquela dos infelizes alienados reclusos nos velhos hospícios.

DOI: 10.35984/fjh.v2i2.191

FAG Journal of Health - ISSN 2674-550X, 2020, v.2, n.2, p. 181 
Os transtornos psiquiátricos têm sido cada vez mais presentes na sociedade moderna, e isso evidencia a importância em valorizar a área que estuda as patologias e a saúde mental do ser humano, a psiquiatria. A OMS define saúde mental como "um estado de completo bem-estar físico, mental e social, e não apenas ausência de doença" (MARQUES et al., 2010) e ainda, "para todas as pessoas, a saúde mental, a saúde física e a social são fios da vida estreitamente entrelaçados e profundamente interdependentes" (MARQUES et al., 2010). À proporção que o conhecimento sobre esse assunto cresce, demonstra-se ainda mais a importância da saúde mental para a qualidade de vida das pessoas e do mundo (MARQUES et al., 2010). Esse tema tem sido discutido pelos estudiosos há anos e ainda não se tem uma explicação concreta.

Segundo Stephen Hinshaw, autor da obra "The Mark of Shame"8, a história da doença mental tem sido dominada pelo confronto entre uma perspectiva sobrenatural/moral da doença mental e a perspectiva científica, bem como entre tratamentos humanos e "tratamentos" punitivos, em diferentes épocas. No mundo grego, Hipócrates contrariou as teorias demonológicas vigentes, que defendiam que a doença mental resulta da possessão por espíritos malignos, em prol de uma concepção médica. Mas a teoria demonológica rapidamente voltou a ser defendida (XAVIER et al., 2014).

Os pacientes psiquiátricos são frequentemente vistos como, perigosos, imprevisíveis, responsáveis pela sua doença, preguiçosos ou vítimas dignas de pena, e esse estereótipo acaba sendo alimentado por uma sociedade que os despreza/estranha (MARQUES et al., 2010).

A psiquiatria é uma área da medicina onde existe um preconceito social que faz com que as patologias da saúde mental sejam algumas vezes subestimadas ou até subdiagnosticadas. Segundo Marques et al, (2010), o estigma frente à doença psiquiátrica está ainda muito consolidado em nossa sociedade, o que prejudica 0 tratamento, a reinserção social e bem- estar desses pacientes. A partir disso, é possível perceber a importância em abordar esse tema, que além de afetar diretamente na qualidade de vida tanto dos pacientes quanto de suas famílias, acaba sendo deixado de lado visto que a própria sociedade resiste em aceitá-los. Corbière et al, (2012) definiu estigma como "um atributo, visível ou não, que denuncia uma imperfeição no indivíduo, que o desqualifica de uma aceitação comunitária plena, resultando em atitudes discriminatórias" (CORBIĖRE et al., 2012). É uma profunda reprovação social devido a características presumidas, crenças ou comportamentos, que não estão de acordo com padrões econômicos, políticos, culturais e sociais impostos por uma sociedade intolerante.

"O estigma da doença mental é um fenômeno tão antigo quanto complexo, cujas definições provêm de diferentes campos do conhecimento, desde a sociologia, à psicologia e a psiquiatria" (XAVIER et al., 2014). Ainda que não exista um consenso no que se refere à definição, não existem controvérsias sobre o impacto que o estigma gera na vida das pessoas com doença mental (XAVIER et al, 2014). De fato, o estigma já foi considerado como "uma segunda doença, e o obstáculo mais importante na provisão de cuidados de saúde mental" (XAVIER et al., 2014).

\section{METODOLOGIA}

Trata-se de um estudo de campo, de caráter quantitativo que utilizou o método dedutivo e teve a coleta de dados através da aplicação de um questionário a estudantes de medicina do Centro Universitário da Fundação Assis Gurgacz e profissionais da área médica. Participaram da pesquisa 98 alunos do $1^{\circ}$ ao $6^{\circ}$ ano do 
curso de medicina e 06 médicos/docentes do Centro Universitário FAG, escolhidos aleatoriamente, de ambos os sexos, de diversas faixas etárias. $100 \%$ dos participantes responderam ao questionário e junto à distribuição desse, foi entregue aos mesmos o Termo de Consentimento Livre e Esclarecido, assinado por todos. Foi utilizado o questionário AQ-9 criado por Corrigan, do qual foram retiradas informações como identificação do participante (idade, gênero, estado civil, existência de filhos), histórico de doença mental referente ao mesmo e seus familiares. Esse questionário pretende medir globalmente o estigma através de nove tópicos: pena, irritação, periculosidade, medo, ajuda, coerção, segregação, e evitamento. Pretendeu- se analisar nove estereótipos acerca da doença mental, sendo constituído por uma descrição de um caso de uma pessoa com esquizofrenia, seguindo-se 9 afirmações ou questões para as quais existe uma escala de Likert de 1 a 9 , em que o 1 corresponde maioritariamente à resposta "não ou nada" e o 9 a "muito ou completamente". O resultado produz um score representativo de cada um dos estereótipos, sendo que o estigma é diretamente proporcional ao valor do score. Admite-se, assim, que um resultado superior a 1 implica existência de estigma.

O trabalho foi aprovado pelo Comitê de Ética em Pesquisa em Seres Humanos do Centro Universitário Assis Gurgacz, o qual estabeleceu parecer favorável sob o número 25764619.3.0000.5219.

\section{RESULTADOS E DISCUSSÃO}

Foi analisada uma amostra de 104 questionários, onde 69 (66,3\%) do sexo feminino e 35 do sexo masculino. As idades distribuíram-se entre um mínimo de 17 e 49 anos. A maior parte dos indivíduos eram solteiros 97 (93,2\%), 6 (5,7\%) eram casados e $1(0,9 \%)$ divorciado. Sendo todos com instrução de ensino superior completo ou incompleto. Em relação ao contato com doença psiquiátrica, 59 (56,7\%) dos respondentes não tinham antecedentes pessoais de doença, enquanto que 45 $(43,2 \%)$ apresentavam. Quando indagados sobre o histórico familiar de doença psiquiátrica $80(76,9 \%)$ mostraram-se positivos, sendo $72(69,2 \%)$ parentes de primeiro grau.

Quando confrontados com o relato de um doente com esquizofrenia, as respostas às perguntas do questionário $A Q-9$, segundo uma escala de likert de 1 a 9 pontos, revelaram posições na sua maioria medianas, como se pode observar no Quadro 1. Nas questões que avaliam a culpa, raiva e evitação do doente, a média das respostas foi inferior a 3. O restante das respostas tiveram uma média entre 4,06 e 7,31 .

Quadro 1. Médias obtidas para as nove questões do AQ-9.

\begin{tabular}{|llll|}
\hline Pena & 5,79 & Raiva & 1,64 \\
Periculosidade & 4,06 & Ajuda & 7,31 \\
Medo & 4,15 & Evitação & 2,46 \\
Culpa & 1,09 & Coerção & 4,44 \\
Segregação & 2,64 & & \\
\hline
\end{tabular}

Considerando que uma pontuação maior que 1 indica a existência do estigma, é possível analisar através da figura 1, que ao longo do curso, as respostas referentes à evitação, raiva, ajuda e culpa são marginalmente constantes. Já em relação a pena 
há uma maior variação entre o $8^{\circ}$ e $11^{\circ}$ período. Segundo a análise do gráfico, a coerção tende a aumentar devido ao exercício da atividade profissional, assim como a periculosidade, que aumentou com uma variação de 0,5 , também devido a atividade profissional.

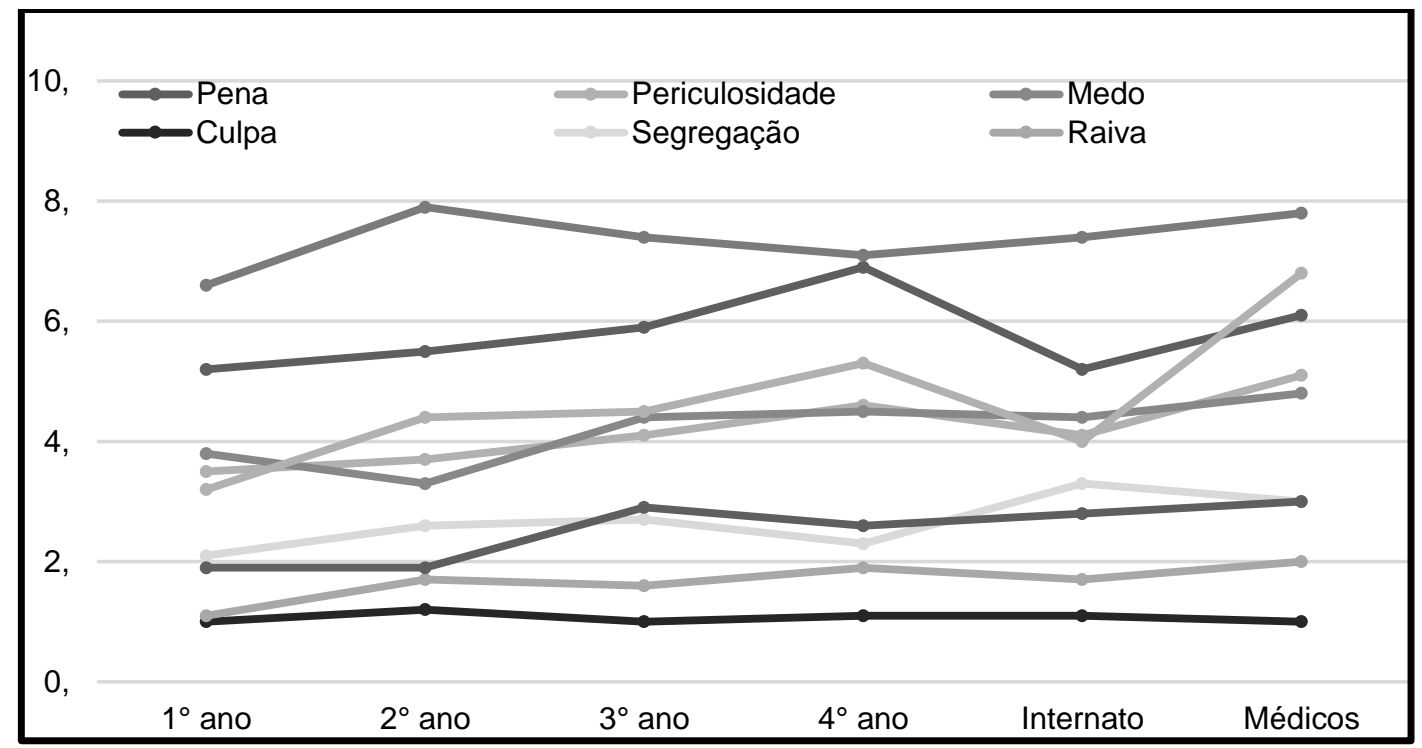

Figura 1. Média das qualidades de acordo com cada grupo

Como a partir da Figura 1 podemos inferir que a instrução acadêmica dentro da medicina não afeta diretamente o estigma, trazemos a Figura 2 para demonstrar que fatores extrínsecos como, em especial, a experiência pessoal ou a experiência familiar afetam de forma mais significativa a existência ou ausência de estigma. Tendo essa informação, podemos deixar essa porta aberta para uma futura pesquisa, que não cabe neste momento, visto que não é o objeto deste trabalho.

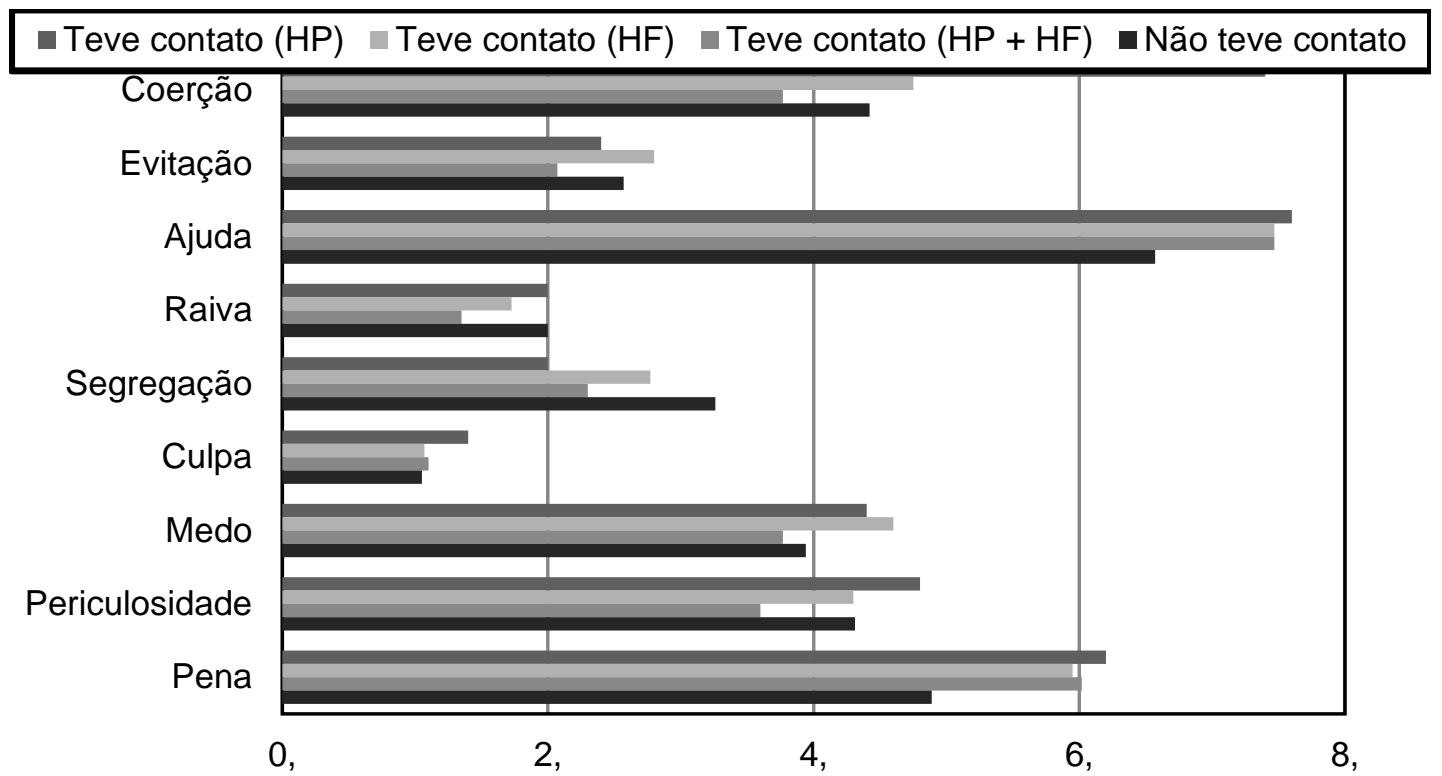

Figura 2. Efeito de fatores extrínsecos na existência ou ausência de estigma 


\section{CONSIDERAÇÕES FINAIS}

Com o intuito de demonstrar e analisar a visão sobre a psiquiatria dentro da área médica, a partir de dados recolhidos através da aplicação de um questionário, este artigo comparou as diferentes visões a respeito da saúde mental ao longo do curso de medicina e da formação médica. Por meio desta discussão e analise dos gráficos, pode-se inferir que a instrução acadêmica não afeta diretamente o estigma que rodeia a psiquiatria.

\section{REFERÊNCIAS}

CONFUNDIMENTO, E. DE; RAMALHO, F. Estudo Observacional. p. 227-234, 2014. DOI: http://dx.doi.org/10.32385/rpmgf.v30i4.11347

CORBIÈRE, M. et al. Strategies to Fight Stigma toward People with Mental Disorders: Perspectives from Different Stakeholders. The Scientific World Journal, v. 2012, p. 1-10, 2012. DOI: 10.1100/2012/516358

MARQUES, A. et al. O Estigma na Doença Mental perspectivado por futuros profissionais de Saúde Mental. Poster apresentado no III Congreso de la Federación Española de Asociaciones de Rehabilitación Psicosocial, 2010. http://dx.doi.org/10.19131/rpesm.0120

ODA, A. M. G. R. Juliano Moreira e a (sua) história da assistência aos alienados no Brasil. Revista Latinoamericana de Psicopatologia Fundamental, v. 14, n. 4, p. 721-727, 2011. https://doi.org/10.1590/1415-47142004001012

ODA, A. M. G. R.; DALGALARRONDO, P. O início da assistência aos alienados no Brasil ou importância e necessidade de estudar a história da psiquiatria. Revista Latinoamericana de Psicopatologia Fundamental, v. 7, n. 1, p. 128-141, 2016. https://doi.org/10.1590/1415-47142004001012

XAVIER, S. et al. O Estigma da doenca menta: Que caminho percorremos? PSi LOGOS, v. 11, p. 10-21, 2014. https://doi.org/10.25752/psi.4102 